\title{
Cost-effectiveness of bazedoxifene versus raloxifene in the treatment of postmenopausal women in Spain
}

This article was published in the following Dove Press journal:

ClinicoEconomics and Outcomes Research

4 July 2013

Number of times this article has been viewed

Josep Darbà'

Nuria Pérez-Álvarez ${ }^{2}$

Lisette Kaskens ${ }^{2}$

Susana Holgado-Pérez ${ }^{3}$

Jill Racketa ${ }^{4}$

Javier Rejas ${ }^{5}$

'Universitat de Barcelona, Barcelona, Spain; ${ }^{2}$ BCN Health Economics and Outcomes Research, Barcelona, Spain; ${ }^{3}$ Hospital Universitari Germans Trias i Pujol, Badalona, Barcelona, Spain; ${ }^{4}$ Global Health Economics and Outcomes Research, Pfizer Inc., Collegeville, PA, USA; ${ }^{5}$ Health Economic and Outcomes Research Department, Pfizer Alcobendas, Madrid, Spain
Correspondence: Josep Darbà Department of Economics, Universitat de Barcelona, Diagonal 690, 08034 Barcelona, Spain

Tel +34934021937

Fax +34934039082

Email darba@ub.edu
Background: The purpose of this study was to assess the cost-effectiveness of bazedoxifene and raloxifene for prevention of vertebral and nonvertebral fractures among postmenopausal Spanish women aged 55-82 years with established osteoporosis and a high fracture risk.

Methods: A Markov model was developed to represent the transition of a cohort of postmenopausal osteoporotic women through different health states, ie, patients free of fractures, patients with vertebral or nonvertebral fractures, and patients recovered from a fracture. Efficacy data for bazedoxifene were obtained from the Osteoporosis Study. The perspective of the Spanish National Health Service was chosen with a time horizon of 27 years. Costs were reported in 2010 Euros. Deterministic results were presented as expected cost per quality-adjusted life-year (QALY), and probabilistic results were represented in cost-effectiveness planes.

Results: In deterministic analysis, the expected cost per patient was higher in the raloxifene cohort $(€ 13,881)$ than in the bazedoxifene cohort $(€ 13,436)$. QALYs gained were slightly higher in the bazedoxifene cohort (14.56 versus 14.54). Results from probabilistic sensitivity analysis showed that bazedoxifene has a slightly higher probability of being cost-effective for all threshold values independent of the maximum that the National Health Service is willing to pay per additional QALY.

Conclusion: Bazedoxifene was shown to be a cost-effective treatment option for the prevention of fractures in Spanish women with postmenopausal osteoporosis and a high fracture risk. When comparing bazedoxifene with raloxifene, it may be concluded that the former is the dominant strategy.

Keywords: osteoporosis, bazedoxifene, raloxifene, vertebral, nonvertebral, fracture, efficacy, costs

\section{Introduction}

Osteoporosis is a frequently occurring disease in postmenopausal women, characterized by low bone mass and microarchitectural deterioration of bone tissue, resulting in increased bone fragility and fracture risk. ${ }^{1,2}$ Osteoporotic fractures commonly occur at the hip, spine, and forearm, with vertebral fractures being the most frequent. ${ }^{3}$ Of all patients who sustain a vertebral fracture, it is estimated that $20 \%$ will suffer a new vertebral fracture within 1 year. ${ }^{4}$ Of all osteoporotic fractures, hip fractures are the most serious, with an elevated mortality risk as well as a high hospital burden in Spain. ${ }^{5}$

Osteoporosis has been a growing economic issue due to the increased number of fractures during the last 20 years, combined with the development of novel agents for the prevention and treatment of osteoporosis. ${ }^{6}$ Aside from the economic 
consequences, osteoporosis also has a negative impact on quality of life for the affected individual. ${ }^{7}$ The high impact of these socioeconomic consequences makes osteoporosis a high priority health problem.

Over the last decade, various new treatments for the prevention of osteoporotic fractures have been developed and approved. Although existing therapies for postmenopausal osteoporosis have been shown to be effective, they may not be appropriate for all women because of concerns related to safety and/or tolerability. ${ }^{8,9}$ One of the currently available therapies is raloxifene, a selective estrogen receptor modulator (SERM) that has been shown to reduce the risk of vertebral fractures in postmenopausal women. ${ }^{10}$ Another selective estrogen receptor modulator, bazedoxifene, has been shown to prevent bone loss and to decrease bone turnover, with a favorable endometrial, ovarian, and breast safety profile in a 2 year, Phase III study of postmenopausal women at risk for osteoporosis. ${ }^{11-13}$ A 3 year, global Phase III study in osteoporotic women aged 55 years, ie, the Osteoporosis Study, ${ }^{14}$ compared bazedoxifene with placebo and raloxifene. Bazedoxifene and raloxifene both reduced the risk of new vertebral fractures compared with placebo. In a post hoc subgroup analysis of patients at higher risk, bazedoxifene significantly reduced the risk of nonvertebral fractures compared with placebo and raloxifene. ${ }^{14}$ Higher-risk patients were defined as women with a femoral neck $\mathrm{T}$ score $\leq-3.0 \mathrm{and} /$ or at least a moderate to severe vertebral fracture or multiple mild vertebral fractures. Many participants in the Osteoporosis Study participated in a 2 year extension study in which bazedoxifene showed sustained efficacy in preventing fractures over 5 years of therapy. ${ }^{15}$

Approximately two million women were estimated to have osteoporosis in Spain in 2010. ${ }^{16}$ It is important to evaluate both clinical and economic implications with the introduction of a new treatment, given that treating this population is associated with a high socioeconomic burden. Clinical aspects are normally investigated in clinical trials within a controlled setting and a limited time frame. In the case of osteoporosis, economic modeling is necessary to study the long-term consequences of fracture risk reduction beyond the time frames of clinical trials.

In Spain, several studies have investigated the socioeconomic impact of treatment of osteoporosis to the Spanish National Health Service, as well as for patients. ${ }^{17-20}$ Cost-effectiveness analyses of osteoporosis vary considerably between countries. ${ }^{18}$ Different tools are being used to estimate fracture risk, which can significantly impact the cost-effectiveness of treatment. A recent cost-effectiveness analysis comparing bazedoxifene with placebo used the FRAX ${ }^{\circledR}$ tool (World Health Organization
Collaborating Centre for Metabolic Bone Diseases, University of Sheffield, Sheffield, UK) that provides fracture probabilities for specific populations. ${ }^{18}$ Although FRAX can be used to predict the probability of hip or other major osteoporotic fractures, the criteria should not be generalized to other countries having different fracture incidence rates and health care costs. ${ }^{21}$ Therefore, when comparing the cost-effectiveness of bazedoxifene with raloxifene in Spanish women with osteoporosis, it is important to take into account that the incidence of fractures is different between southern European countries and countries in the Scandinavian region. ${ }^{22,23}$ The objective of this study was to compare the cost-effectiveness of bazedoxifene and raloxifene in the prevention of vertebral and nonvertebral fractures in women diagnosed with osteoporosis. The analysis is based on the Osteoporosis Study ${ }^{14}$ and applied to the Spanish setting.

\section{Materials and methods Model specifications}

The computer simulation model in Microsoft ${ }^{\circledR}$ (Microsoft Corporation, Redmond, WA, USA) Excel used to calculate cost-effectiveness was an updated Markov model that has been used previously to estimate the cost-effectiveness of bazedoxifene incorporating the FRAX algorithm from a European perspective. ${ }^{18}$ The model represented the transition of a cohort of postmenopausal women with osteoporosis and aged 55 years through various health states with occurrence of events based on yearly probabilities. The starting age was based on women recruited for a 3 year clinical study of bazedoxifene. ${ }^{14}$ The analysis was performed from the health care perspective, following all patients from initiation of treatment until they were 82 years of age and had received bazedoxifene or raloxifene for this 27 -year time period. It was assumed that no patient discontinued treatment because of adverse effects.

The model consisted of six health states. All patients began in the "well health" or "no event state". In each cycle, a patient had a probability of sustaining a fracture, remaining healthy, or dying. After 1 year in any fracture state, the patient had a risk of sustaining a new fracture or dying. If a patient died, she would move to the dead-health state and remain there for the rest of the simulation. After 1 year, the patient moved to the corresponding post-fracture state if no additional fracture occurred. The patient would automatically remain in the post-fracture state (shown as a circular arrow in Figure 1) if she did not die or sustain a new fracture. Fractures could be vertebral or nonvertebral, with half consisting of hip fractures and half consisting of wrist fractures. After a nonvertebral fracture, it was possible 


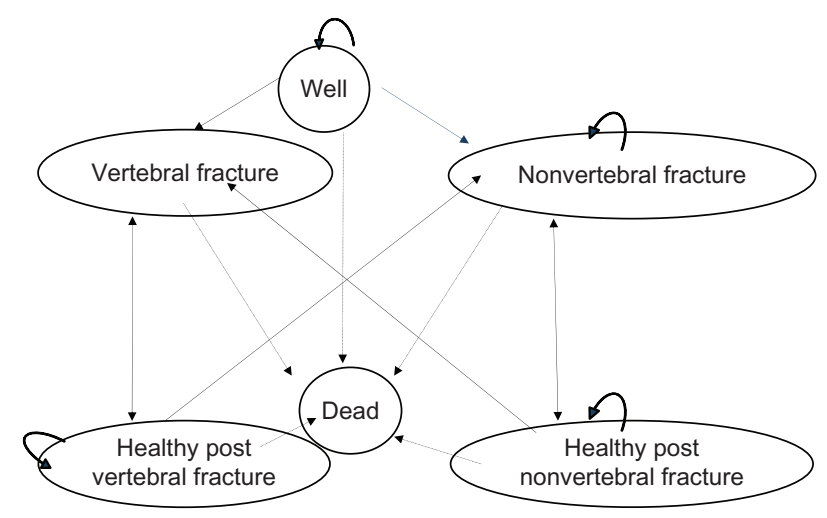

Figure I Graphic representation of the model.

to sustain a vertebral fracture or another nonvertebral fracture.

\section{Target patient groups, efficacy, and side effects}

The Osteoporosis Study ${ }^{14}$ was a 3-year, randomized, doubleblind, placebo-controlled and active-controlled trial including 7,492 healthy postmenopausal osteoporotic women aged 55-82 years. All women were at least 2 years postmenopausal and had osteoporosis. Osteoporosis was defined as low bone mineral density with a $\mathrm{T}$ score between -2.5 and -4.0 , or radiographically confirmed vertebral fractures and lumbar spine and femoral neck bone mineral density $\mathrm{T}$ scores not worse than -4.0 . Women were excluded if they had diseases that may affect bone metabolism, conditions that could interfere with bone mineral densitometry, pathologic vertebral fractures, vasomotor symptoms requiring treatment, or serious conditions (endometrial hyperplasia or carcinoma, abnormal vaginal bleeding, malignancy within 10 years of the study, endocrine disorders requiring treatment, or untreated malabsorption disorders). Women with an active or past history of deep vein thrombosis, pulmonary embolism, or retinal vein thrombosis were also excluded, as were subjects with elevated fasting total cholesterol or triglyceride levels ( $\geq 310 \mathrm{mg} / \mathrm{dL}$ or $\geq 300 \mathrm{mg} / \mathrm{dL}$, respectively). Use of androgens, systemic estrogen (except for estriol $2.0 \mathrm{mg} /$ day), topical estrogen (more than three times per week), progestagens, selective estrogen receptor modulators, bisphosphonates, calcitonin, parathyroid hormone, and cholecalciferol (>50,000 IU/week) was prohibited within 6 months of screening.

Subjects were assigned to treatment using a computerized randomization/enrolment system, which assigned unique randomization and package numbers. Randomization was stratified by prevalent vertebral fracture status to ensure a similar distribution of subjects with and without vertebral fractures across the treatment groups.

The study was conducted in accordance with the ethical principles of the Declaration of Helsinki and was approved by the clinical ethics research committee or institutional review board at each institution.

Patients were randomly assigned to each treatment group and received at least one dose of study medication, ie, bazedoxifene $20 \mathrm{mg}$ daily $(\mathrm{n}=1886$ ), bazedoxifene $40 \mathrm{mg}$ daily $(\mathrm{n}=1872)$, raloxifene $60 \mathrm{mg}$ daily $(\mathrm{n}=1849)$, or placebo $(n=1885)$ for 36 months. From the total number of eligible patients, the proportion of patients completing the study was $66 \%$ for those receiving bazedoxifene $20 \mathrm{mg}$ or $40 \mathrm{mg}$ daily, $68 \%$ for those receiving bazedoxifene $60 \mathrm{mg}$ daily, and $67 \%$ for those receiving placebo. Approximately $56 \%$ of participants in each treatment group had at least one vertebral fracture at baseline, and the majority had one mild vertebral fracture. The base-case populations in this study for the comparison of bazedoxifene and raloxifene were based on a subgroup of high-risk patients with a $\mathrm{T}$ score $\leq-3.0$ or at least one moderate fracture or multiple mild vertebral fractures. Patients receiving bazedoxifene $20 \mathrm{mg}$ daily or raloxifene $60 \mathrm{mg}$ daily were compared.

For osteoporotic patients without fractures, a relative risk reduction for vertebral fractures of $35 \%$ (95\% confidence interval [CI] 0.32-1.30) was seen in patients treated with bazedoxifene versus $41 \%$ (95\% CI $0.29-1.21)$ for those treated with raloxifene (Table 1). Relative risk reductions were $45 \%$ (95\% CI $0.32-0.94)$ for bazedoxifene versus $43 \%(95 \%$ CI $0.34-0.97)$ for raloxifene in patients with previous vertebral fractures (Table 1). No differences in the incidence of nonvertebral fractures were observed between either treatment in women without prior fractures, although the reduced relative risk in high-risk patients with previous fractures was $46 \%$ with bazedoxifene and $8 \%$ with raloxifene.

Bazedoxifene and raloxifene were associated with a number of adverse events, including leg cramps, venous thrombolytic events such as deep vein thrombosis, and breast cysts/fibrocystic breast disease. ${ }^{14}$ To account for these adverse events, costs and utilities for each health state were corrected based on their incidences. The incidence of leg cramps was significantly different between the groups, with an incidence of $10.9 \%$ on bazedoxifene versus $11.7 \%$ on raloxifene $(P<0.01)$. The incidence of deep vein thrombosis was $0.4 \%$ in both groups and the incidence of breast cysts/ fibrocystic breast disease was 0.7 in the bazedoxifene group and $1.7 \%$ in the raloxifene group $(P<0.05)$. 
Table I Transition probabilities for bazedoxifene $20 \mathrm{mg} /$ day and raloxifene $60 \mathrm{mg} / \mathrm{day}$

\begin{tabular}{|c|c|c|c|c|c|c|}
\hline Bazedoxifene & Well & $\begin{array}{l}\text { Vertebral } \\
\text { fracture }\end{array}$ & $\begin{array}{l}\text { Nonvertebral } \\
\text { fracture }\end{array}$ & $\begin{array}{l}\text { Healthy } \\
\text { nonvertebral } \\
\text { fracture }\end{array}$ & $\begin{array}{l}\text { Healthy } \\
\text { nonvertebral } \\
\text { fracture }\end{array}$ & Dead \\
\hline Well & $0.94479^{a}$ & $0.0090 \mathrm{I}^{\mathrm{b}, \mathrm{c}}$ & $0.024^{\mathrm{b}, \mathrm{d}}$ & 0 & 0 & $0.022^{\mathrm{e}}$ \\
\hline Vertebral fracture & 0 & 0 & 0 & $0.9768120^{\mathrm{a}}$ & 0 & $0.023188^{\mathrm{e}}$ \\
\hline Nonvertebral fracture & 0 & 0 & $0.1384667^{b, f}$ & 0 & $0.8351333^{\mathrm{a}}$ & $0.0264^{\mathrm{g}}$ \\
\hline Healthy vertebral fracture & 0 & $0.0275706^{\mathrm{b}, \mathrm{h}}$ & $0.1986292^{\mathrm{b}, \mathrm{i}}$ & $0.7506122^{\mathrm{a}}$ & 0 & $0.023188^{j}$ \\
\hline Healthy nonvertebral fracture & 0 & $0.0103615^{b}$ & $0.0528313^{h}$ & 0 & $0.9126072^{\mathrm{a}}$ & $0.0242^{k}$ \\
\hline Dead & 0 & 0 & 0 & 0 & 0 & 1 \\
\hline Raloxifene & Well & & & & & \\
\hline Well & $0.944994^{\mathrm{a}}$ & $0.008806^{\mathrm{b}, \mathrm{c}}$ & $0.024^{b, d}$ & 0 & 0 & $0.022^{\mathrm{e}}$ \\
\hline Vertebral fracture & 0 & 0 & 0 & $0.9768120^{\mathrm{a}}$ & 0 & $0.023188^{\mathrm{e}}$ \\
\hline Nonvertebral fracture & 0 & 0 & $0.1897467^{b, f}$ & 0 & $0.7838533^{\mathrm{a}}$ & $0.0264^{g}$ \\
\hline Healthy vertebral fracture & 0 & $0.0271577^{\mathrm{b}, \mathrm{h}}$ & $0.2287228^{\mathrm{b}, \mathrm{i}}$ & $0.7209315^{\mathrm{a}}$ & 0 & $0.023188^{j}$ \\
\hline Healthy nonvertebral fracture & 0 & $0.0100682^{b}$ & $0.0608356^{h}$ & 0 & $0.90489624^{a}$ & $0.0242^{k}$ \\
\hline Dead & 0 & 0 & 0 & 0 & 0 & 1 \\
\hline
\end{tabular}

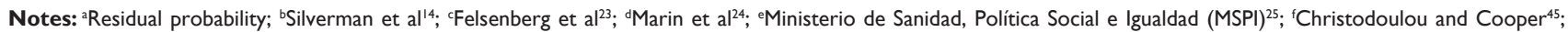

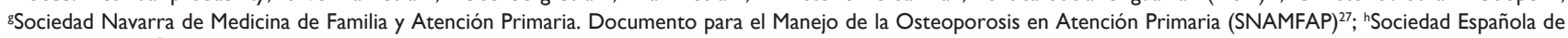
Investigaciones Óseas y Metabolismo Mineral (SEIOMM) ${ }^{7}$; 'Naves et a ${ }^{46}$; 'Agència d'Informació, Avaluació i Qualitat en Salut. (AIAQS) ${ }^{26}$; ${ }^{2}$ Borgstrom et al ${ }^{33}$. All probabilities without notes are based on assumption.

\section{Incidence and fracture risk}

Country-specific and age-specific normal population incidences were used when possible. A vertebral fracture can be classified as a clinical fracture (ie, symptomatic fractures that come to clinical attention) or as a morphometric fracture, which includes all fractures, both symptomatic and asymptomatic. The morphometric definition of a fracture was used for this study because it provided more specific incidence data, with an age-standardized incidence ratio of $10.2(95 \% \mathrm{CI}$ 4.7-15.7) per 1000 habitants for the female southern European population because clinical fracture data were lacking. ${ }^{23}$

Incidence rates for nonvertebral fractures (ratio $24.2[95 \%$ CI 21.70-26.70]) nonvertebral fractures per 1,000 female inhabitants) were obtained from Marín et $\mathrm{a}^{24}$ and consisted mostly of wrist fractures (36.7\%) and hip fractures (14.9\%). Population fracture incidence rates were adjusted to reflect the risk in each treatment group.

The probability of having a new fracture, a second fracture, or remaining healthy was determined by the relative risk of vertebral or nonvertebral fractures affected by treatment with bazedoxifene or raloxifene based on the Osteoporosis Study ${ }^{14}$ (Table 1).

\section{Mortality}

Age-specific normal population mortality rates were obtained from the Spanish National Statistics Agency. ${ }^{25}$ These were adjusted in the model to take into account mortality associated with fractures. ${ }^{18}$ In this analysis, we derived estimates of the excess mortality after vertebral fractures from a study based on Spanish patients which showed an increase in mortality of $20 \%-34 \%$ within 5 years of the fracture. ${ }^{26}$ The relative risk in the year after a vertebral fracture was estimated at 5.4 and was similar in subsequent years. The relative risk of mortality in the year after a nonvertebral fracture was $20 .{ }^{27}$ The relative risk of excess mortality in the years subsequent to a nonvertebral fracture were estimated at 30 , mostly attributable to hip fractures, although there are studies which claim there is little or no relationship between comorbid conditions and post-fracture mortality. ${ }^{17}$ Based on this study, a relative risk of 10 was assumed for patients who sustained a nonvertebral fracture in subsequent years, because these not only included hip fractures but also wrist fractures.

\section{Quality of life}

Utility weights were derived from a global longitudinal study of 57,141 postmenopausal osteoporotic women aged 55 years and older that examined health-related quality of life in women who sustained fractures and the effect of fracture location on their quality of life. ${ }^{28}$ Utility values were elicited using the EQ-5D ${ }^{\circledR}$ and Short-Form 36 subscales mapped to a country-specific preference-based value. The reduction in quality of life after a vertebral fracture was 38\% lower than that observed in a healthy individual. Reduction in quality of life after a nonvertebral fracture estimated based on reductions for hip and wrist fractures was 39\%, of which $55 \%$ was caused by hip fractures. Reduction in quality of life in the years following a vertebral fracture was $9 \%$ lower than that of a healthy individual. A $6 \%$ reduction in quality of life was estimated for hip and wrist fractures in the years following a nonvertebral fracture. 
Venous thrombolytic events, primarily deep vein thrombosis, were assumed to be associated with a $10 \%$ utility loss per year based on assumptions in previous publications. ${ }^{29,30}$ No appropriate estimate was found for utility loss due to leg cramps and breast cysts/fibrocystic breast disease. A similar 10\% decrease in quality of life was assumed for leg cramps and breast cysts/fibrocystic breast disease as for deep vein thrombosis in all health states. Based on the incidence rates of adverse events for both treatments, utilities were corrected for the decrease in quality of life associated with adverse events (Table 2).

\section{Costs}

Treatment costs for osteoporosis consisted of drug costs, diagnostic and follow-up tests, and physician visits. Costs were represented in 2010 Euros and discounted according to health economic guidelines, resulting in a $3 \%$ discount for costs and benefits. ${ }^{31}$ Drug tariffs were derived from a Spanish drug cost database. ${ }^{32}$ Drug costs for bazedoxifene were assumed to be similar to those for raloxifene. Monitoring of treatment for osteoporosis was estimated to include annual physician visit and annual bone mineral density measurement, based on other studies and expert opinion..$^{33,34}$

Event-related fracture resource utilization was obtained by expert consultation. Vertebral fractures were assumed to be associated with 2 days of hospitalization. Outpatient treatment comprised of two imaging procedures, three specialist visits, and concomitant medication such as analgesics over 90 days. Vertebral fracture costs resulted in approximately $€ 3878$ per event.

Nonvertebral fracture costs were assumed to consist of $50 \%$ hip fractures and $50 \%$ wrist fractures. Hip fractures were associated with 15 hospitalization days and similar

Table 2 Utilities

\begin{tabular}{llll}
\hline Health condition & Utility $^{\mathrm{a}}$ & $\begin{array}{l}\text { Corrected utility for adverse } \\
\text { events }\end{array}$ \\
\cline { 3 - 4 } & & Bazedoxifene & Raloxifene $^{\mathrm{b}}$ \\
\hline Well & $\mathrm{I}$ & 0.996 & 0.9954 \\
$\begin{array}{l}\text { Vertebral fracture } \\
\text { Nonvertebral fracture }\end{array}$ & 0.620 & 0.61752 & 0.617148 \\
$\begin{array}{l}\text { Healthy post vertebral } \\
\text { fracture }\end{array}$ & 0.910 & 0.647898 & 0.6475077 \\
$\begin{array}{l}\text { Healthy post } \\
\text { nonvertebral fracture }\end{array}$ & 0.940 & 0.9358416 & 0.905814 \\
$\begin{array}{l}\text { QoL loss due to each } \\
\text { adverse event of } 10 \% \text {, d, }, *\end{array}$ & -0.1 & - & - \\
\hline
\end{tabular}

Notes: *Includes assumption; ${ }^{\text {AAdachi et }}$ al ${ }^{28}$; ${ }^{\text {bSilverman et }}$ al ${ }^{14}$; Sobocki et al ${ }^{29}$; 'Zethraeus et $\mathrm{al}^{30}$.

Abbreviation: QoL, quality of life. outpatient treatment to that for vertebral fractures, including additional rehabilitation costs during a 40-day period. Wrist fractures included four hospitalization days, surgery costs, and outpatient treatment similar to that for hip fractures, with one less imaging procedure. Nonvertebral fracture costs were estimated at $€ 7,478$ per event (Table 3).

Resource utilization associated with the treatment of adverse events such as leg cramps, deep vein thrombosis, and breast cysts/fibrocystic breast disease, was added to all health states based on the treatment-related incidence and expert validation (Table 4). Treatment of leg cramps and breast cysts/fibrocystic breast disease was associated with one diagnostic test and one specialist physician visit per year. Management of deep vein thrombosis included several diagnostic tests, a specialist physician visit, and use of concomitant medication.

Table 3 Osteoporosis treatment and fractures: resource utilization in units and costs

\begin{tabular}{|c|c|c|}
\hline & Units & Cost (EUR) \\
\hline & & 2010 \\
\hline \multicolumn{3}{|l|}{ Treatment } \\
\hline Drug costs & & $287^{a}$ \\
\hline Conventional blood test & I & $21^{\mathrm{b}}$ \\
\hline Bone density scan & 1 & $165^{c}$ \\
\hline Visit to rheumatologist & 1.5 & $69^{d}$ \\
\hline Annual treatment costs & & 576 \\
\hline \multicolumn{3}{|l|}{ Vertebral fracture } \\
\hline $\begin{array}{l}\text { Hospitalization vertebral fracture } \\
\text { (average } 2 \text { days) }\end{array}$ & & $3,513.90^{\mathrm{e}}$ \\
\hline Radiography & I & $32.80^{f}$ \\
\hline Bone scan & I & $232.34^{8}$ \\
\hline Visit to orthopedic surgeon & 2 & $44.10^{d}$ \\
\hline Analgesics (2 tablets/day, 90 days) & & $0.06^{\mathrm{a}}$ \\
\hline Annual treatment costs & & 3878 \\
\hline \multicolumn{3}{|l|}{ Nonvertebral fracture } \\
\hline \multicolumn{3}{|l|}{ Hip fracture } \\
\hline Hospitalization hip fracture (average & & $7,956.70^{\mathrm{e}}$ \\
\hline \multicolumn{3}{|l|}{15 days) } \\
\hline Visits to orthopedic surgeon & 3 & $44.10^{d}$ \\
\hline Radiography & 2 & $32.80^{f}$ \\
\hline Rehabilitation (40 days) & & $52.87^{b}$ \\
\hline Analgesics ( 2 tablets/day, 90 days) & & $0.06^{\mathrm{a}}$ \\
\hline \multicolumn{3}{|l|}{ Wrist fracture } \\
\hline Surgery & I & $96.97^{\mathrm{h}}$ \\
\hline $\begin{array}{l}\text { Hospitalization wrist fracture } \\
\text { (average of } 4 \text { days) }\end{array}$ & 4 & $555.7 I^{d}$ \\
\hline Visits to orthopedic surgeon & 3 & $44.10^{\mathrm{d}}$ \\
\hline Radiography & 3 & $32.80^{f}$ \\
\hline Rehabilitation (40 days) & & $52.87^{\mathrm{b}}$ \\
\hline Analgesics ( 2 tablets/day, during 90 days) & & $0.06^{\mathrm{a}}$ \\
\hline $\begin{array}{l}\text { Annual treatment costs ( } 50 \% \text { hip } \\
\text { and } 50 \% \text { wrist) }\end{array}$ & & 7478 \\
\hline
\end{tabular}

Notes: ${ }^{2}$ Vademecum ${ }^{32}$; ${ }^{b}$ Hospital Lluís Alcanyis ${ }^{47}$; ${ }^{c}$ Hospital de la Esperanza ${ }^{48}$; ${ }^{d}$ Instituto Nacional de la Salud (INSALUD) ${ }^{49}$; eFinnern and Sykes ${ }^{50}$; 'Cernuda ${ }^{51}$; 8Diari Oficial de la Generalitat de Catalunya (DOGC) $)^{52}$; ${ }^{\text {DOGC }}{ }^{53}$. 
Table 4 Adverse events: resource utilization in units and costs

\begin{tabular}{lll}
\hline Adverse events & Units & $\begin{array}{l}\text { Cost }(\boldsymbol{\epsilon}) \\
2010\end{array}$ \\
\hline Leg cramps & & $39^{\mathrm{a}}$ \\
Basic analyses: blood, biochemistry, electrolytes & $\mathrm{I}$ & $46^{\mathrm{b}}$ \\
Visit to specialist physician & $\mathrm{I}$ & 85 \\
Annual treatment costs & & \\
Deep vein thrombosis & $\mathrm{I}$ & $39^{\mathrm{a}}$ \\
Basic analyses: blood, biochemistry, ions & $\mathrm{I}$ & $70^{\mathrm{b}}$ \\
Doppler echocardiogram & $\mathrm{I}$ & $11 \mathrm{I}^{\mathrm{b}}$ \\
Plethysmography of legs & $\mathrm{I}$ & $79^{\mathrm{b}}$ \\
Venography & $\mathrm{I}$ & $46^{\mathrm{b}}$ \\
Visit to specialist physician & $1.83^{\mathrm{c}}$ \\
Heparin sodium (injection $5000 \mathrm{UI} / \mathrm{mL}$, & \\
5 days) & & $2.30^{\mathrm{c}}$ \\
Warfarin (5 mg/day, 40 days ) & & 349 \\
Annual treatment costs & & $128^{\mathrm{b}}$ \\
Breast cysts/fibrocystic breast disease & $\mathrm{I}$ \\
Mammography & $\mathrm{I}$ & $46^{\mathrm{b}}$ \\
Visit to specialist physician & & 174 \\
Annual treatment costs &
\end{tabular}

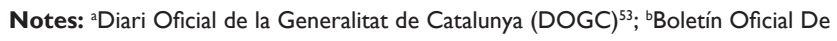
La Rioja (BOR) $)^{54}$; c Vademecum ${ }^{32}$.

\section{Analyses}

In this study, quality-adjusted life-years (QALYs) gained was included as an effectiveness measure to allow us to compare the value of the interventions across different disease states. The incremental cost-effectiveness ratio (ICER), which is a measure of the cost per QALY gained in this study, is defined as:

$$
\text { ICER }=\frac{\Delta C}{\Delta E}=\frac{\mathrm{C} \text { bazedoxifene }-\mathrm{C} \text { raloxifene }}{\text { E bazedoxifene }-\mathrm{E} \text { raloxifene }}
$$

where $\Delta C$ is the difference in cost between treatment with bazedoxifene and raloxifene and $\Delta E$ is the difference in effectiveness (QALYs) between each treatment. The ICER could be computed from the main outputs, cost, and QALYs in this model.

The variation in effects, in terms of both reduced fracture risk and utilities, as well as direct health care costs, was included in the probabilistic sensitivity analysis, which was done using statistical distributions to capture parameter uncertainty. We used beta and gamma distributions for probabilities and costs, respectively. The results from 1000 cohort iterations were presented as cost-effectiveness acceptability curves and as a scattered plot in the incremental cost-effectiveness plane.

\section{Results}

The base-case analysis consisted of postmenopausal women with established osteoporosis aged 55 years. Health care costs for treatment of osteoporosis and fractures per patient were similar for both treatment groups but, corrected for the incidence of adverse events, resulted in a slightly higher event cost for raloxifene than for bazedoxifene (Table 5).

Deterministic results using a 27-year horizon showed that the expected cost per patient was higher in the raloxifene cohort $(€ 13,436)$ than in the bazedoxifene cohort $(€ 13,381$, Table 6). The estimated gain in QALYs was slightly higher in the bazedoxifene cohort than in the raloxifene cohort (14.56 versus 14.54). The ICER showed bazedoxifene to be the dominant treatment strategy, being less costly (by €444) and more effective (+0.03 QALYs) compared with raloxifene.

\section{Sensitivity analysis}

The probabilistic analysis showed a large variation in both costs and effects when introducing uncertainty around the input parameters. Cost-effectiveness acceptability curves showed that treatment with bazedoxifene had a higher probability of being cost-effective than treatment with raloxifene using alternative values up to $€ 50,000$ for the maximum willingness to pay for an additional QALY gained by the National Health Service (Figure 2). If taking into account the commonly, albeit not officially, accepted willingness-to-pay threshold of $€ 30,000$ for a QALY in the health care sector in Spain, ${ }^{35}$ bazedoxifene is a cost-effective option.

The mean incremental QALY and cost gain amounted to 0.16 and $-€ 428$, respectively, which showed that bazedoxifene was the dominant treatment strategy (Figure 3). The incremental costs were scattered on both sides of the $x$ axis, indicating that bazedoxifene generates cost savings ( $52 \%$ of observations were below the $x$ axis). Fifty-one percent of the observations were located on the right of the $y$ axis, indicating observations where the gain in QALYs was higher for bazedoxifene. According to the probabilistic sensitivity analysis, bazedoxifene generated greater health benefit in terms of QALYs gained, but at less cost.

Table 5 Annual cost per health state

\begin{tabular}{llll}
\hline Health state & $\begin{array}{l}\text { Cost }(€) \\
2010\end{array}$ & $\begin{array}{l}\text { Corrected costs for adverse } \\
\text { events }\end{array}$ & Raloxifene \\
\cline { 2 - 4 } & & 580 & 581 \\
Well & 576 & 4458 & 4459 \\
Vertebral fracture & 3878 & 8058 & 8059 \\
$\begin{array}{l}\text { Nonvertebral fracture } \\
\text { Healthy post vertebral }\end{array}$ & 7478 & 580 & 581 \\
fracture & & 580 & 581 \\
$\begin{array}{l}\text { Healthy post } \\
\text { nonvertebral fracture }\end{array}$ & 576 & & \\
\hline
\end{tabular}


Table 6 Total cost, incremental costs, QALY, QALYs gained, and ICER

\begin{tabular}{llllll}
\hline Treatment & $\begin{array}{l}\text { Cost } \\
(€)\end{array}$ & $\begin{array}{l}\text { Incremental } \\
\text { costs }\end{array}$ & $\begin{array}{l}\text { QALY } \\
\text { QALYs } \\
\text { gained }\end{array}$ & $\begin{array}{l}\text { ICER } \\
(€ / Q A L Y)\end{array}$ \\
\hline Bazedoxifene & 13,436 & $-444 €$ & 14.56 & +0.02 & Dominant \\
Raloxifene & $|3,88|$ & & 14.54 & & \\
\hline
\end{tabular}

Abbreviations: QALY, quality-adjusted life-years; ICER, incremental costeffectiveness ratio.

\section{Discussion}

This study investigated the cost-effectiveness of bazedoxifene compared with raloxifene in postmenopausal Spanish women with osteoporosis using effectiveness data from the Osteoporosis Study. ${ }^{14}$ The results of this study indicate that bazedoxifene was the dominant treatment strategy compared with raloxifene for the prevention of vertebral and nonvertebral fractures in high-risk postmenopausal osteoporotic women aged 55-82 years.

Probabilistic sensitivity analysis that accounted for parameter uncertainty confirmed the deterministic results. Treatment with bazedoxifene demonstrated a higher probability of being cost-effective than treatment with raloxifene up to a maximum of $€ 50,000$ for willingness to pay for an additional QALY gained.

Although no guidelines are available in Spain to determine whether an intervention can be considered cost-effective, a nonofficial threshold of $€ 30,000$ for a QALY is considered acceptable, and compares favorably with other medical and surgical procedures. ${ }^{35}$ When this threshold is taken into account, bazedoxifene was a cost-effective treatment option compared with raloxifene.

Any conclusions from this study need to be placed into the context of assumptions made for this model. Important issues to consider are the epidemiology, morbidity, and mortality associated with vertebral and nonvertebral fractures, as well as adverse events arising from both treatments. These issues have been addressed as much as possible by assuming

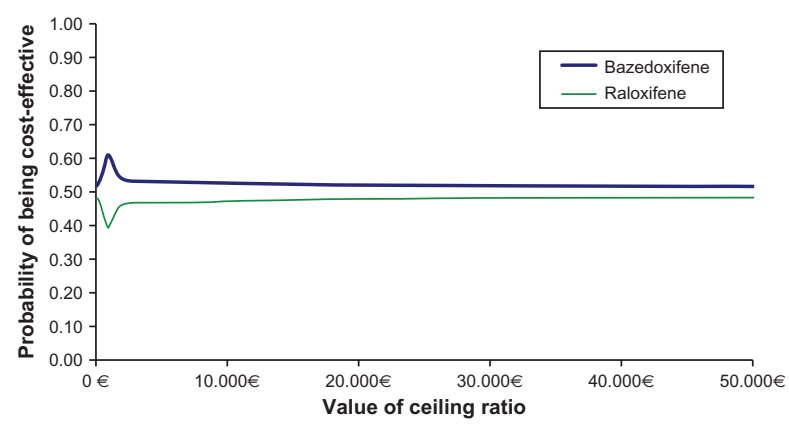

Figure 2 Cost-effectiveness acceptability curves: bazedoxifene versus raloxifene.

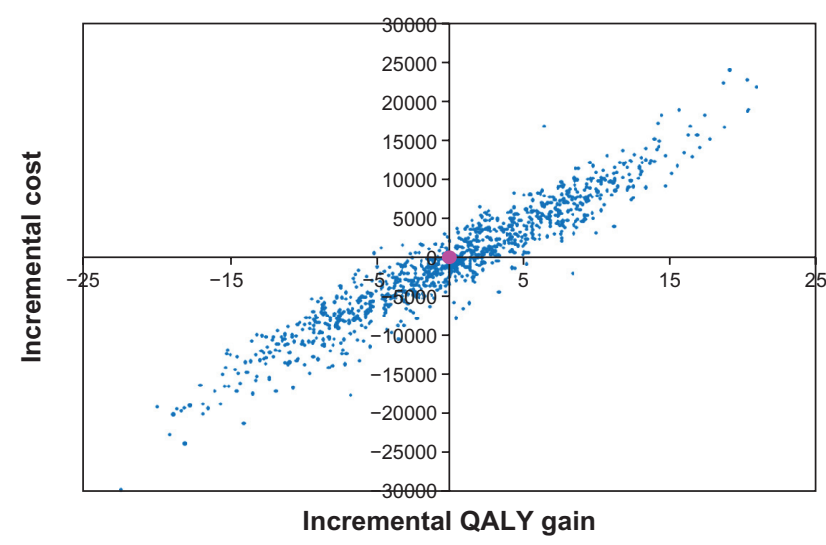

Figure 3 Cost-effectiveness of bazedoxifene versus raloxifene in postmenopausal women with osteoporosis.

Abbreviation: QALY, quality-adjusted life-years.

conservative scenarios or by including a probabilistic sensitivity analysis.

The general conclusions of this study are primarily based on vertebral and nonvertebral fracture outcomes and the effect of adverse events associated with both treatments. From our results, it is apparent that the effect of treatment on fracture risk and adverse events related to both treatments are important drivers for cost-effectiveness.

In the base case, treatment effects for the prevention of vertebral fractures and nonvertebral fractures with or without previous fractures were based on a head-to-head comparison of bazedoxifene with raloxifene. ${ }^{14}$ Relative risk reductions for vertebral fractures were higher for the raloxifene cohort, although relative risks were lower for patients in the bazedoxifene cohort who had sustained earlier vertebral and nonvertebral fractures. Differences in relative risk reduction for nonvertebral fractures after prior fractures were larger and more favorable for bazedoxifene. No treatment effect was assumed for nonvertebral fractures in patients without fractures because the fracture incidence did not differ significantly from placebo. ${ }^{14}$ Similar results were found comparing raloxifene with placebo in the Multiple Outcomes of Raloxifene Evaluation study. ${ }^{10}$ If effects on nonvertebral fractures in patients without prior fractures were included, these could further improve cost-effectiveness.

Adverse events associated with both treatments were obtained from the Osteoporosis Study. ${ }^{14}$ The main effect observed was a decrease in quality of life for affected patients and associated treatment costs incurred by patients. Similar findings for loss of quality of life because of adverse events were reported in studies of raloxifene. ${ }^{10,36}$ An increased incidence of venous thrombolytic events, primarily deep vein thrombosis, was observed in the bazedoxifene and 
raloxifene groups, a finding consistent with that reported in earlier studies. ${ }^{36,37}$ Further, bazedoxifene was associated with a lower incidence of breast cyst/fibrocystic breast disease compared with raloxifene. All adverse events were assumed to cause a $10 \%$ decrease in quality of life in the first year and subsequent years because appropriate estimates for utility loss were lacking in the literature. When the utilities were corrected for decrease in quality of life, the QALY gain was higher for the bazedoxifene cohort, leading to better costeffectiveness. Other estimates of decrease in quality of life could influence cost-effectiveness ratios.

The incidence of breast cancer in the study reported by Silverman et $\mathrm{al}^{14}$ was low for bazedoxifene and raloxifene, and no significant differences were observed in the incidence of breast cancer between the treatment groups. In the same study, ${ }^{14}$ treatment with bazedoxifene was associated with fewer cases of breast cancer than treatment with raloxifene over a period of 3 years, although these results were not significant. These results contrast with previous reports that raloxifene is associated with a reduction in breast cancer risk. ${ }^{37-39}$ Although different studies, as mentioned before, report possible effects of bazedoxifene and raloxifene on risk of breast cancer, any decrease in quality of life due to breast cancer for the second and following years after having breast cancer, as reported by Zethraeus et al, ${ }^{40}$ has not been included in this model. Including decrease in quality of life because of breast cancer, might affect the cost-effectiveness ratio, and would improve for bazedoxifene based on the lower number of cases observed, as was seen in the study reported by Silverman et al. ${ }^{14}$

An important strength of this study is that data on incidence of events, post-event mortality, and costs were country-specific. Apart from its strengths, there were also several limitations to the study. We only included patients who sustained a vertebral or nonvertebral fracture, and there were no data included for patients who could have sustained multiple fractures simultaneously. Therefore, the effect of multiple fractures in terms of costs and quality of life could not be determined.

Regarding data on quality of life, a limitation of this study was the lack of references for loss of quality of life as a result of adverse events, such as leg cramps and breast cysts/fibrocystic breast disease. Decrease in quality of life because of deep vein thrombosis was based on assumptions made in previous studies, ${ }^{28,29}$ although supportive evidence was lacking.

The effects of poor adherence and persistence were not investigated in this study. Adherence tends to be higher in clinical trials than in clinical practice. Although data on adherence are available for raloxifene, ${ }^{41}$ no data outside of clinical trials are available for bazedoxifene. Overall adherence with treatment for osteoporosis has been shown to be poor. ${ }^{42,43}$ As a consequence of nonoptimal persistence, the number of fractures avoided could be reduced, results in less QALY gain for the treatment population. Another effect is the reduction in intervention costs when treatment is stopped before the planned treatment duration. Therefore, less persistence could lead to less effectiveness, which might be compensated for somewhat by lower intervention costs, meaning persistence is likely to have a small effect on cost-effectiveness ratios, which is in line with the results of Jonsson et al. ${ }^{44}$

Whether bazedoxifene is a cost-effective treatment depends largely on the probability of having a nonvertebral fracture, sustaining a subsequent nonvertebral fracture, and decreased quality of life due to adverse events, as well as the amount the Spanish National Health Service is willing to pay for a QALY gained. Bazedoxifene compared with raloxifene in this study was shown to fall below the threshold of $€ 30,000$ for an intervention that demonstrates typical benefits in Spain. It is important to recognize that the present study was undertaken in a Spanish setting and that the results are not automatically applicable elsewhere, given that fracture risk, mortality, and costs may differ from country to country.

\section{Conclusion}

Bazedoxifene was shown to be a cost-effective treatment option for the prevention and treatment of fractures in postmenopausal osteoporotic women with a high fracture risk in Spain. When comparing bazedoxifene with raloxifene, it may be concluded that bazedoxifene is the dominant treatment strategy. Results of probabilistic sensitivity analysis show that the choice of the optimal strategy of bazedoxifene is independent of the maximum that the Spanish National Health Service is willing to pay per additional QALY. Bazedoxifene demonstrated a slightly higher probability of being cost-effective for all threshold values.

\section{Disclosure}

Nuria Pérez-Álvarez and Lisette Kaskens are employees of BCN Health Economics and Outcomes Research, Barcelona, Spain, a consultancy hired by Pfizer Inc, to develop the economic model and the manuscript. Josep Darbà was involved as an external advisor hired by Pfrizer Inc. from the Universitat de Barcelona and responsible for the development, review of the model, comments and review of the manuscript. Susana Holgado-Pérez reports no conflict 
of interest in this work. Jill Racketa was an employee of Pfizer Inc, at the time of this study, and Javier Rejas is an employee of Pfizer SLU. The authors wish to thank Roger Lou, a former employee of Pfizer Inc, for his assistance in the logistic part of the study and comments and review of the manuscript. Additional editorial support was provided by Bo Choi of MedErgy and funded by Pfizer Inc.

\section{References}

1. NIH Consensus Development Panel. Osteoporosis prevention, diagnosis, and therapy. JAMA. 2001;285:785-795.

2. Koda-Kimble MA, Young LY, Alldredge BK, et al. Applied Therapeutics Clinical Use of Drugs, 9th ed. Philadelphia, PA: Wolters Kluwer Health/ Lippincott Williams \& Wilkins; 2009.

3. Sosa M, Gómez de Tejada MJ, Hernández Hernández D. Concepto, clasificación, factores de riesgo y clínica de la osteoporosis. [Concept, classification, risk factors and clinics of osteoporosis]. Rev Esp Enf Metab Oseas. 2001;10:7-11. Spanish.

4. Melton LJ III, Atkinson EJ, Cooper C, O'Fallon WM, Riggs BL. Vertebral fractures predict subsequent fractures. Osteoporos Int 1999;10:214-221.

5. Bouza C, López T, Palma M, Amate JM. Hospitalised osteoporotic vertebral fractures in Spain: analysis of the national hospital discharge registry. Osteoporos Int. 2007;18:649-657.

6. Cooper C, Campion G, Melton LJ III. Hip fractures in the elderly: a world-wide projection. Osteoporos Int. 1992;2:285-289.

7. Sociedad Española de Investigaciones Óseas y Metabolismo Mineral (SEIOMM) Osteoporosis postmenopáusica. Guía de práctica clínica. [Spanish Society for Bone Research and Mineral Metabolism. Postmenopausal osteoporosis. Clinical practice guideline] 2003. Rev Clin Esp. 2003;203(10):496-506.

8. MacLean C, Newberry S, Maglione M, et al. Systematic review: comparative effectiveness of treatments to prevent fractures in men and women with low bone density or osteoporosis. Ann Intern Med. 2008;148:197-213.

9. Lewiecki EM. Emerging drugs for postmenopausal osteoporosis. Expert Opin Emerg Drugs. 2009;14:129-144.

10. Ettinger B, Black DM, Mitlak BH, et al; for the Multiple Outcomes of Raloxifene Evaluation (MORE) Investigators. Reduction of vertebral fracture risk in postmenopausal women with osteoporosis treated with raloxifene: results from a 3-year randomized clinical trial. JAMA. 1999;282:637-645.

11. Arun B, Anthony M, Dunn B. The search for the ideal SERM. Expert Opin Pharmacother. 2002;3:681-691.

12. Miller PD, Chines AA, Christiansen C, et al. Effects of bazedoxifene on BMD and bone turnover in postmenopausal women: 2-yr results of a randomized, double-blind, placebo-, and active-controlled study. J Bone Miner Res. 2008;23:525-535.

13. Pinkerton JV, Archer DF, Utian WH, et al. Bazedoxifene effects on the reproductive tract in postmenopausal women at risk for osteoporosis. Menopause. 2009;16:1102-1108.

14. Silverman SL, Christiansen C, Genant HK, et al. Efficacy of bazedoxifene in reducing new vertebral fracture risk in postmenopausal women with osteoporosis: results from a 3-year, randomized, placebo-, and active-controlled clinical trial. J Bone Miner Res. 2008;23: 1923-1934.

15. de Villiers TJ, Chines AA, Palacios S, et al. Safety and tolerability of bazedoxifene in postmenopausal women with osteoporosis: results of a 5-year, randomized, placebo-controlled phase 3 trial. Osteoporos Int. 2011;22:567-576.

16. Del Pino Montes J. Epidemiología de las fracturas osteoporóticas: las fracturas vertebrales y no vertebrales. [Epidemiology of osteoporotic fractures: Vertebral fractures and non-vertebral fractures]. Rev Osteoporos Metab Miner. 2010;2:S8-S12. Spanish.
17. Strom O, Borgstrom F, Sen SS, et al. Cost-effectiveness of alendronate in the treatment of postmenopausal women in 9 European countries - an economic evaluation based on the fracture intervention trial. Osteoporos Int. 2007;18:1047-1061.

18. Borgstrom F, Strom O, Kleman M, et al. Cost-effectiveness of bazedoxifene incorporating the $\mathrm{FRAX}(\mathrm{R})$ algorithm in a European perspective. Osteoporos Int. 2011;22:955-965.

19. Instituto de Salud Carlos III, Análisis coste-utilidad de los tratamientos farmacológicos para la prevención de fracturas en mujeres con osteoporosis en ESPAÑA. [Cost-utility analysis of pharmaceutical treatments for the prevention of fractures in women with osteoporoisis in Spain]. Informe Público de Evaluación de Tecnologías Sanitarias IPE 63/2010 [Public report for the Evaluation of Health Technologies IPE 63/2010]. Available from: http://www.isciii.es/htdocs/publicaciones/documentos/63. Accessed May 13, 2011. Spanish.

20. Darba J, Restovic G, Kaskens L, et al. Patient preferences for osteoporosis in Spain: a discrete choice experiment. Osteoporos Int. 2011;22:1947-1954.

21. Sanfelix-Genoves J, Peiro S, Sanfelix-Gimeno G, et al. Development and validation of a population-based prediction scale for osteoporotic fracture in the region of Valencia, Spain: the ESOSVAL-R study. $B M C$ Public Health. 2010;10:153.

22. Ismail AA, Pye SR, Cockerill WC, et al. Incidence of limb fracture across Europe: results from the European Prospective Osteoporosis Study (EPOS). Osteoporos Int. 2002;13:565-571.

23. Felsenberg D, Silman AJ, Lunt M, et al. Incidence of vertebral fracture in Europe: results from the European Prospective Osteoporosis Study (EPOS). J Bone Miner Res. 2002;17:716-724.

24. Marín F, Gonzalez-Macias J, Moya R, et al. Fragility nonspinal fractures in a cohort of 5,201 women aged 65 years and older during a 3-year follow-up. Med Clin (Barc). 2006;127:401-404. Spanish.

25. Ministerio de Sanidad, Política Sociale Igualdad(MSPI), Series 1981-2007: Mortalidad por causa de muerte, España y comunidades autónomas. [Series 1981-2007: Mortality by mortality cause, Spain and Autonomous Regions]. Available from: http://www.msc.es/estadEstudios/ estadisticas/estadisticas/estMinisterio/mortalidad/seriesTablas.htm. Accessed April 26, 2011. Spanish.

26. Agència d'Informació, Avaluació i Qualitat en Salut. Guía de Práctica Clínica sobre Osteoporosis y Prevención de Fracturas por Fragilidad. 2010. Guías de Práctica Clínica en el SNS: AATRM No 2007/02. [Agency of Information, Evaluation and Quality in Health. Clinical practice guideline on osteoporosis and prevention of fragility fractures. 2010. Clinical guidelines of the NHS: AATRM N $\left.{ }^{\circ} 2007 / 02\right]$. Available from: http://www.gencat.cat/salut/depsan/units/aatrm/pdf/gpc_osteoporosi_ aatrm2010_vcompleta.pdf. Accessed May 13, 2011. Spanish.

27. Sociedad Navarra de Medicina de Familia y Atención Primaria. Documento para el Manejo de la Osteoporosis en Atención Primaria (Actualización Diciembre 2006). [Navarran Society of Family Medicine and Primary Care. Report for the management of osteoporosis in Primary Care (updated December 2006)]. Available from: http://www. guiasalud.es/GPC/GPC_363.pdf. Accessed April 29, 2011. Spanish.

28. Adachi JD, Adami S, Gehlbach S, et al. Impact of prevalent fractures on quality of life: baseline results from the global longitudinal study of osteoporosis in women. Mayo Clin Proc. 2010;85:806-813.

29. Sobocki P, Lekander I, Borgstrom F, Strom O, Runeson B. The economic burden of depression in Sweden from 1997 to 2005. Eur Psychiatry. 2007;22:146-152.

30. Zethraeus N, Borgstrom F, Jonsson B, Kanis J. Reassessment of the cost-effectiveness of hormone replacement therapy in Sweden: results based on the Women's Health Initiative randomized controlled trial. Int J Technol Assess Health Care. 2005;21:433-441.

31. Pinto JL, Sanchez F, Métodos para la evaluación económica de nuevas prestaciones. [Methods for the economic evaluation of new services]. Editado por: Centre de Recerca en Economía i Salut - Cres y Ministerio de Sanidad y Consumo, España [Edited by: Centre for Economics and Health - Cres and Ministry of Health and Consumption, Spain]. Available from: http://www.msc.es. Accessed April 29, 2011. Spanish. 
32. Vademecum.es. [Drug cost database]. Available from: http://www. vademecum.es/. Accessed April 29, 2011. Spanish.

33. Borgstrom F, Jonsson B, Strom O, Kanis JA. An economic evaluation of strontium ranelate in the treatment of osteoporosis in a Swedish setting: based on the results of the SOTI and TROPOS trials. [Methods for the economic evaluation of new services]. Osteoporos Int. 2006;17:1781-1793.

34. Jonsson B, Christiansen C, Johnell O, Hedbrandt J. Cost-effectiveness of fracture prevention in established osteoporosis. Osteoporos Int. 1995;5:136-142.

35. Sacristán JA, Oliva J, del Llano J, Prieto L, Pinto JL. What is an efficient health technology in Spain?. Gac Sanit. 2002;16:334-343. Spanish.

36. Cummings SR, Eckert S, Krueger KA, et al.The effect of raloxifene on risk of breast cancer in postmenopausal women: results from the MORE randomized trial. Multiple Outcomes of Raloxifene Evaluation. JAMA. 1999;281:2189-2197.

37. Grady D, Ettinger B, Moscarelli E, et al. Safety and adverse effects associated with raloxifene: multiple outcomes of raloxifene evaluation. Obstet Gynecol. 2004;104:837-844.

38. Barrett-Connor E, Mosca L, Collins P, et al. Effects of raloxifene on cardiovascular events and breast cancer in postmenopausal women. N Engl J Med. 2006;355:125-137.

39. Vogel VG, Costantino JP, Wickerham DL, et al. Effects of tamoxifen vs raloxifene on the risk of developing invasive breast cancer and other disease outcomes: the NSABP Study of Tamoxifen and Raloxifene (STAR) P-2 trial. JAMA. 2006;295:2727-2741.

40. Zethraeus N, Johannesson M, Jonsson B. A computer model to analyze the cost-effectiveness of hormone replacement therapy. Int J Technol Assess Health Care. 1999;15:352-365.

41. Ziller V, Wetzel K, Kyvernitakis I, Seker-Pektas B, Hadji P. Adherence and persistence in patients with postmenopausal osteoporosis treated with raloxifene. Climacteric. 2011;14:228-235.

42. Siris ES, Harris ST, Rosen CJ, et al. Adherence to bisphosphonate therapy and fracture rates in osteoporotic women: relationship to vertebral and nonvertebral fractures from 2 US claims databases. Mayo Clin Proc. 2006;81:1013-1022.

43. Papaioannou A, Ioannidis G, Adachi JD, et al. Adherence to bisphosphonates and hormone replacement therapy in a tertiary care setting of patients in the CANDOO database. Osteoporos Int. 2003;14: $808-813$.

44. Jonsson B, Strom O, Eisman JA, et al. Cost-effectiveness of denosumab for the treatment of postmenopausal osteoporosis. Osteoporos Int. 2011;22:967-982.

45. Christodoulou C, Cooper C. What is osteoporosis? Postgrad Med J. 2003;79:133-138
46. Naves M, az-Lopez JB, Gomez C, Rodriguez-Rebollar A, RodriguezGarcia M, Cannata-Andia JB. The effect of vertebral fracture as a risk factor for osteoporotic fracture and mortality in a Spanish population. Osteoporos Int. 2003;14:520-524.

47. Hospital Lluís Alcanyis, Memoria 2000. [Lluís Alcanyis hospital, Note 2000]. Available from: http://www.ctv.es/USERS/vgisbertj/home.html. Accessed May 3, 2011. Spanish.

48. Hospital de la Esperanza, Tarifario 1995, Hospital de la Esperanza, Barcelona, 1995. [Esperanza Hospital, Tariffs 1995 of Hospital Esperanza, 1995]. Spanish.

49. Instituto Nacional de la Salud, Resultados de la gestión analítica en los hospitales del INSALUD GECLIF 2000. [National Health Institute, Results of the analytical management in hospitals of INSALUD GECLIF 2000] Subdirección General de Coordinación Administrativa, Hospitales INSALUD, Madrid, 2001. Spanish.

50. Finnern HW, Sykes DP. The hospital cost of vertebral fractures in the EU: estimates using national datasets. Osteoporos Int. 2003;14:429-436.

51. Cernuda C. Coste de consultas externas: visitas y pruebas. [Costs of external visits: visits and tests]. Todo Hospital, $\mathrm{n}^{\circ} 153$ Enero/Febrero, 1999, H. Universitario Josep Trueta, Girona, 1999. Spanish.

52. Diari Oficial de la Generalitat de Catalunya. Departament de Sanitat i Seguretat Social. Orden de 29 de Septiembre de 1997; núm. 2504. [Official Journal of the Generality of Catalonia. Department of Health and Social Security. Order of 29th of September 1997]. Spanish.

53. Diari Oficial de la Generalitat de Catalunya. Institut Català de la Salut. Departament de Salut. RESOLUCIÓN SLT/383/2009, de 21 de enero, sobre la revisión de precios públicos correspondientes a los servicios sanitarios que presta el Instituto Catalán de la Salud. [Official Journal of the Generality of Catalonia. Catalonian department of health. Department of Health. Resolution SLT/383/2009, 21st of January, concerning the review of public tariffs corresponding to health services by the Catalan Health Institute]. Febrero 2009; núm. 5325. Available from: https://www.gencat.cat/eadop/imagenes/5325/09042029.pdf. Accessed March 3, 2011. Spanish.

54. Boletín Oficial De La Rioja. Consejería de Salud. Resolución del Consejero de Salud por la que se dispone la publicación de las tarifas por servicios sanitarios prestados a particulares en los centros del Servicio Riojano de Salud. [Official Journal of the Rioja. Health council. Resolution by the health council by which it disposes over the publication of tariffs for health services to patients in Riojan health centers]. Febrero 2009; núm. 27. Available from: http://www2. larioja.org/pls/dad_user/G04.texto_integro?p_cdi_accn=443-230928. Accessed March 3, 2011. Spanish.
ClinicoEconomics and Outcomes Research

\section{Publish your work in this journal}

ClinicoEconomics \& Outcomes Research is an international, peerreviewed open-access journal focusing on Health Technology Assessment, Pharmacoeconomics and Outcomes Research in the areas of diagnosis, medical devices, and clinical, surgical and pharmacological intervention. The economic impact of health policy and health systems

\section{Dovepress}

organization also constitute important areas of coverage. The manuscript management system is completely online and includes a very quick and fair peer-review system, which is all easy to use. Visit $\mathrm{http}: / /$ www.dovepress.com/testimonials.php to read real quotes from published authors. 